\title{
Bullying e sua relação com o suicídio na adolescência
}

\author{
Ana Karoline Lôbo Barbosal ; Thereza Denise Luna Parente²; Martha Maria Macêdo Bezerra ${ }^{3}$; \\ Thércia Lucena Grangeiro Maranhão ${ }^{4}$
}

\begin{abstract}
Resumo: O presente artigo faz uma análise sobre o fenômeno bullying e sua relação com o suicídio em adolescentes. Para tanto, verifica-se conceitos sobre o fenômeno que podem levar jovens a cometer suicídio e sua relação com a autoestima na adolescência. O objetivo do trabalho é analisar o fenômeno bullying e sua relação com o suicídio, assim como estudar causas que podem levar jovens ao suicídio e também analisar a relação entre bullying, autoestima e suicídio na adolescência. A pesquisa deste artigo foi de ordem qualitativa, baseada em livros e artigos científicos. Contudo, conclui-se que o bullying é um fenômeno que acontece em todo o mundo, que suas consequências são graves, atingindo principalmente a autoestima da vítima e que casos de suicídio entre adolescentes envolvendo este fenômeno estão crescendo. A pesquisa não pretende esgotar as discussões sobre o tema, mas contribuir e trazer evidências sobre o assunto valorizando suas articulações.
\end{abstract}

Palavras - chave: Bullying. Suicídio. Adolescência.

\section{Bullying and its relationship to suicide in adolescence}

Abstract: This article makes an analysis about the bullying phenomenon and its relation to the suicide in teenagers. For both, it turns out some concepts about the phenomenon that may lead young people to commit suicide and its relationship to self-esteem in adolescence. Are addressed also theories about the knowledge of yourself in children until the beginning of adolescence and the violence occurring within the bullying phenomenon. The research for this article was based on qualitative order books and scientific articles. With everything, it is concluded that bullying is a phenomenon that happens in the world, its consequences are severe, affecting mainly the victim's self-esteem and suicide cases among teens involving this phenomenon is growing increasingly. The survey is not intended to exhaust the discussions on the topic, but contribute to bring more evidence on the subject and your joints.

Key-words: Bullying. Suicide. Adolescence

\section{Introdução}

O fenômeno denominado bullying é muito evidenciado nos dias de hoje e pode ser relacionado, em alguns casos, com o suicídio.

\footnotetext{
${ }^{1}$ Graduanda do curso de Psicologia da Faculdade Leão Sampaio - FALS - Email: anakaroline.lobobarbosa@ yahoo.com.br

2 Pedagoga pela Universidade Regional do Cariri. Especialista em Arte Educação.

${ }^{3}$ Mestrado em Educação pela Universidade Estadual do Ceará. Pedagoga pela Universidade Regional do Cariri, Especialização em Língua Portuguesa pela Universidade Estadual do Ceará, Especialização em Políticas Públicas pela Universidade Regional do Cariri, Especialisação em Saude Mental e Psiquiatria pela Universidade Estadual do Vale do Acaraú. Atualmente, cursa o Doutorado em Saúde Coletiva pela Faculdade de Medicina do ABC. Professora concursada da Secretaria de Educação do Estado do Ceará e Professora da Rede Municipal de Juazeiro do Norte, CE. E-mail: marthamacedo2016@gmail.com

${ }^{4}$ Professora Especialista do curso de Psicologia da Faculdade Leão Sampaio. Email: thércia@ leaosampaio.edu.br
} 
Tal forma de violência realizada dentro desse fenômeno pode ser associado à sensação de poder no indivíduo que pratica o bullying e afeta a vítima trazendo dor, desconforto, insegurança e angústia, podendo causar danos, sendo um deles, o suicídio.

Albino e Terencio (2012) relatam que os EUA, Noruega, Portugal e Espanha são países de maior porcentagem no desenvolvimento de pesquisas sobre o tema bullying. Um dos países que enfrentam o bullying mais de perto e um dos mais ricos do mundo, os EUA, sofre muito com esse fenômeno afetando os adolescentes do mesmo.

Segundo Calbo (et al., 2009) casos de homicídios e suicídio acontecem muito constantemente nos adolescentes por conta da pressão que o adolescente vítima do bullying sofre. Alguns estudos indicam que o bullying ocorre entre a faixa etária de nove e quinze anos de idade. Efeitos decorrentes da violência causada na criança ou no adolescente, sendo a mesma direta ou indireta, trazem, muitas vezes, consequências para a vida adulta da vítima do bullying.

A maioria das vítimas desse fenômeno encontra-se em estado de pressão psicológica. É a partir dessa pressão sofrida que o adolescente se vê sem saída e a única maneira de poder aliviar este sofrimento seria tirando sua própria vida ou matando o causador de tudo isso. Para ser considerado bullying, a vítima tem que ter sofrido entre dois ou mais episódios consecutivos. A sequência desses episódios pode levar o indivíduo que sofre desse fenômeno a se estressar e não suportar mais tal pressão sofrida.

Analisando sobre este pensamento, Feijó (et al.,1999) traz que, o aumento nas taxas de tentativa de suicídio em adolescentes, têm levado à intensificação de muitos fatores de risco, entre eles, os eventos estressores.

Sobre esta ideia do autor acima, podemos dizer que as tentativas de suicídio são um indício que algo não vai bem e que o adolescente que se encontra em crise por conta do seu sofrimento causado pelo bullying comete esse ato para aliviar seu sofrimento ou para mostrar aos demais que o mesmo está sofrendo e pedindo ajuda.

O bullying é um tema muito discutido em nosso país e no mundo todo, não só nas escolas, mas em vários outros lugares como nas academias, nas Universidades, nas redes sociais. Suas consequências são grandes e temos que estar atentos e ter conhecimento profundo do que seja o bullying e todos os fenômenos que o rodeiam.

Pode-se relacionar ao bullying e ao suicídio, a baixa autoestima que afeta muitos os adolescentes e, com isso, os deixa mais suscetíveis ao fato. 
Para Coopersmith (1967 apud ASSIS, et al., 2006), compreende-se que a autoestima é um juízo pessoal de valor. É uma experiência subjetiva pela qual as pessoas têm acesso através de relatos verbais e comportamentos.

Assim, pode-se dizer que a autoestima como um juízo pessoal e como uma experiência subjetiva, está nas atitudes do indivíduo consigo mesmo e, quando isto é afetado, gera problemas emocionais.

Segundo Assis (et al., 2006), os adolescentes, vítimas do bullying geralmente são pessoas com dificuldades para reagir diante das situações agressivas que sofrem e, com isso, pode ocorrer a evasão escolar, já que, muitas vezes, não conseguem suportar a pressão.

O interesse no tema surge através da curiosidade pessoal de estudos mais aprofundados sobre o fenômeno e sua relação com o suicídio, na tentativa de favorecer indiretamente os adolescentes que sofrem com ele, tanto para o conhecimento sobre o mesmo, como para evitar que este se agrave devido o desconhecimento geral. Partindo desse pressuposto, serão abordadas questões sobre o bullying e sua relação com o suicídio.

Logo, surgiu a seguinte pergunta: O bullying pode levar ao suicídio da vítima? Acreditase na hipótese de que os suicídios entre adolescentes têm ocorrido por conta de episódios envolvendo o bullying.

Amparada nos estudos acima, a pesquisa tem como objetivo principal analisar o fenômeno bullying e sua relação com o suicídio; assim como estudar causas que podem levar jovens ao suicídio e também analisar a relação entre bullying, autoestima e suicídio na adolescência.

$\mathrm{Na}$ execução desse artigo foi realizado um levantamento bibliográfico através de publicações científicas de artigos e livros relacionadas ao tema.

Sobre o bullying, ele acontece na maioria das vezes de forma silenciosa e cabe a nós termos informações sobre o mesmo e estarmos preparados e prevenidos, pois ele ocorre constantemente e está em quase todos os lugares com diferentes formas de manifestações. 
Id on Line Revista Multidisciplinar e de Psicoloqia

Id on Line Multidisciplinary Journal and Psycology

\section{Bullying}

Para Colovini e Costa (2007) se usa a palavra inglesa bullying, porque na Língua Portuguesa não há um amplo significado para o mesmo. Em alguns comportamentos, o bullying se faz presente, como por exemplo, bater, xingar, humilhar e excluir.

“O bullying ocorre entre iguais. Está relacionado a atitudes agressivas, intencionais e que se repetem, causando dor e angústia. Pode se manifestar em um simples apelido.” (TREVISOL e DRESCH, 2011, p.42).

O bullying é um fenômeno existente em todos os lugares que vivemos. Até na nossa família pode existir casos do mesmo, mas os lugares mais afetados com esse fenômeno são as escolas e as redes sociais na internet.

“O termo bullying não possui tradução literal para o português. Bully é o termo, em inglês, para "valentão" e bullying pode ser traduzido por "intimidação [...] comportamento de ameaças e intimidações". (LISBOA et al., 2009, p. 60).

Comportamentos carregados com bullying podem gerar imensas consequências para o desenvolvimento escolar da criança ou adolescente.

De acordo com Colovini e Costa (2007) os envolvidos nesse tipo de situação se classificam em três categorias. Os autores, que são aqueles que praticam a violência; as vítimas ou alvos, que são os que sofrem a violência e as testemunhas, que são aqueles que não praticam e nem sofrem com o bullying, mas convivem no ambiente em que o fenômeno ocorre e são testemunhas do mesmo.

Para Rebelo (2007) é correto afirmar que o bullying é praticado por todas as classes sociais, tanto nas escolas públicas, como nas particulares e pode se manifestar verbalmente, fisicamente e psicologicamente.

Dessa forma Almeida, Silva e Campos (2008) afirmam que "existem dois tipos de prática do bullying: a direta e a indireta. A direta seria: ameaçar; bater [...] roubar pertences. A indireta seria: espalhar boatos maldosos, isolar a vítima da sociedade". (p.10)

Para Freire e Aires (2011) o bullying é um fenômeno social de grande relevância e deve ser analisado a partir de cada contexto, sempre considerando a subjetividade da vítima, como as características sociais, econômicas e culturais. 
"São estarrecedores os inúmeros dramas juvenis. Fatos no Brasil e no mundo evidenciam uma realidade perversa: os jovens estão, cada vez mais, no palco de grandes tragédias $[\ldots]$ sendo alvo de atrocidades.” (BALBINO, 2008, p.149)

Brincadeiras de mau gosto podem ser bullying, mas quando a vítima que sofre do mesmo deixa a situação ficar mais grave e mais profunda, acaba gerando uma grande série de violências e perturbações.

Leão (2010) traz a seguinte afirmação:

\begin{abstract}
A prática desse tipo de violência é vista pelos os autores dedicados a esse assunto como "Fenômeno bullying". Tal fenômeno apresenta-se de forma velada, intencional e repetitiva, dentro de uma relação desigual de poder, por um longo período de tempo contra uma mesma vítima, sem motivos evidentes, adotando comportamentos cruéis, humilhantes e intimidadores, gerando consequências irreparáveis, sejam elas físicas, psíquicas, emocionais ou comportamentais. (p. 119)
\end{abstract}

Essas consequências são irreparáveis, a ponto de deixar feridas imensas na vítima que sofre com o bullying tanto fisicamente, como psicologicamente, não só na escola, mas em todos os outros locais aonde esse fenômeno acontece.

Segundo Leão (2010), as consequências provocadas pelo bullying podem gerar danos e traumas terríveis na vida da criança, sendo eles: a baixa autoestima, estresse, depressão, queda no rendimento escolar, pensamentos de vingança contra o agressor e até mesmo o próprio suicídio.

Corroborando com essa ideia, Campos e Jorge (2010, p.109) afirmam que "[...] as ameaças, os insultos, os apelidos cruéis e as gozações que magoam profundamente [...] resulta em formas físicas de agressão, como empurrões, beliscões, cusparadas, etc".

Portanto, como referido anteriormente, é através dessas ameaças e insultos que o problema do bullying começa, muitas vezes em forma de brincadeiras e que vão ficando mais pesadas até gerar um desconforto na vítima e maior autoridade no agressor diante da mesma.

Muitos casos acontecem quando a vítima contém algum problema ou deformidade, seja ele físico ou emocional. Mas, na maioria das vezes, os insultos são relacionados ao físico. Muitas pessoas tem uma deformidade facial, que é um dos motivos para o fenômeno acontecer. Kovács (et al., 2008, p.127) traz que a deformidade e mutilação no rosto de uma pessoa, que é a expressão de identidade máxima, rompe todos os padrões de beleza e estética, deforma e mutila o indivíduo ao ponto do mesmo conviver com um estigma e viver em situação de 
Id on Line Revista Multidisciplinar e de Psicoloqia

Id on Line Multidisciplinary Journal and Psycology

desacreditado. E, além disso, que toda pessoa deseja ter um rosto e um corpo agradável, que todos queiram olhar e admirar.

O rosto é um aspecto crucial no corpo do indivíduo. Muitos adolescentes já nasceram com deformidades faciais, outros já passaram por cirurgias pelo qual deformam o seu rosto. Segundo Kóvacs (et al., 2008, p.127), as pessoas que já nasceram com deformidades faciais ficam mais satisfeitas com intervenções de cirurgias, pois seria uma forma de se distanciar da sua imagem do passado e se aproximar de uma imagem idealizada pelo indivíduo. Pessoas que tem o rosto deformado por questões decorrentes de traumas costumam ficar insatisfeitas com as intervenções cirúrgicas, pois se dão conta de que estão cada vez mais distantes da imagem anterior e, na maioria desses casos, veem sua imagem anterior como um objetivo a ser alcançado e um modelo para o mesmo.

Sobre a aparência, que é uma das razões pelo qual o bullying acontece, Kóvacs ( $e t$ al., 2008, p.128) traz que a mesma é muito importante para relacionamentos interpessoais e muito cruelmente determinada pela sociedade, em que a mesma impõe um certo tipo de aparência para o indivíduo e ela é fundamentada através dos conceitos de beleza impostos pela mídia, pelos meios de comunicação, pelo outro e pelo espelho.

\section{Bullying e autoestima: impacto na adolescência}

O bullying é cometido em muitos lugares, até mesmo em nossa própria casa junto com a família, mas o local mais agravante desse fenômeno de acordo com casos e pesquisas envolvendo o mesmo é, sem dúvida, a escola.

De acordo com Leão (2010), sobre a escola, ele traz que o "ambiente que deveria ser agradável e sadio tem sido palco de atitudes frequentes, que envolvem atos de violência entre os alunos, ficando evidente, dessa forma, a conduta bullying”. (pág. 119).

Lisboa (2005) vem trazer que o comportamento agressivo dentro da escola não é um problema recente. O comportamento agressivo surge como todo comportamento que tem um intuito de causar prejuízos ou danos na vítima. E para Hawley (1999), alguns dos comportamentos agressivos durante a adolescência são esperados e podem ter benefícios adaptativos. 
Outro cenário muito visto nos casos envolvendo o bullying é o cyberbullying. D’Urso (2015) relata que o cyberbullying seria um meio de compreender as agressões e humilhações por meios eletrônicos, seja ele por e-mail, sites de relacionamentos, conversas instantâneas, anonimamente ou não e redes sociais. O cyberbullying surgiu como uma variante do tradicional bullying e o mesmo vem sendo definido pelo recurso às tecnologias como meios para humilhar, denegrir e difamar as pessoas, seja ela uma ou mais.

Para Steinberg (1999 apud BANDEIRA; HUTZ, 2010) o conceito de autoestima tem sido estudado e considerado como um fator importante para a saúde mental na adolescência. Existe uma relação entre autoestima, rendimento escolar e aprovação social e essa relação é generalizável a todos os grupos culturais e étnicos.

Por tanto, acredita-se que os adolescentes que têm baixa autoestima desenvolvem mecanismos que distorcem a comunicação de seus sentimentos e pensamentos, dificultando a integração grupal, segundo Coopersmith e Rosenberg (1989 apud BANDEIRA; HUTZ, 2010).

O bullying implica em diferentes formas na autoestima de meninos e meninas envolvidos nos diferentes papéis e variações da mesma nos diferentes papéis para o mesmo sexo, segundo Bandeira e Hutz (2010).

Observa-se que, na adolescência, a crise de identidade se encontra nessa época. Vítimas do bullying sentem a sua autoestima prejudicada por causa de muitas brincadeiras apelidandoos ou xingando-os. A crise de identidade aparece quando a autoestima está baixa e o adolescente se sente confrontado em relação ao que ele quer realmente ser, por conta de estar triste e sem defesa acerca do problema enfrentado por causa do bullying que afetou sua autoestima.

Segundo Field (1999 apud LIMA, 2007), há quatro tipos de problemas que caracterizam o bullying: arrelia, exclusão, tiranizar físico e a perseguição. Por isso, o mesmo vem trazer que:

\footnotetext{
Alguns problemas enfrentados pelo Bullying são: Arrelia - Arreliar é violência verbal. É o mais perigoso e mais duradouro modo de tiranizar. Os meios mais comuns da arrelia são relacionados à aparência, sexualidade e aprovação social. Exclusão - A exclusão é baseada na manipulação social, e podem ser expressados abertamente "você não pode se sentar conosco". O objetivo da exclusão é criar uma identidade do grupo que se transforme em um mecanismo de controle poderoso. Físico - O tiranizar físico envolve regularmente atacar alguém que é mais fraco. Pode ser diretamente agressivo, como a batida, o retrocesso e cuspir; ou indireto, como pelo gesto e a propriedade de desfiguração ou escondendo. Perseguição - A perseguição envolve geralmente perguntas repetidas, irritantes, indicações ou ataques sobre opções sexuais, do gênero racial, as religiosas ou da nacionalidade (p. 02 - 03).
} 
Em acordo como citado acima, o bullying implica mais na questão física, xingamentos em relação ao seu corpo, como por exemplo, se uma determinada menina for gorda já é chamada de "gordinha", "baleia" e outros determinados apelidos. Já os meninos podem ser afetados em relação a sua sexualidade, seu modo de se vestir, seu físico também é afetado e sua pele, caso tenha o aparecimento de espinhas. Sua sexualidade em relação a ser chamado de "gay" pelo modo de agir ou se vestir, seu físico por ser magro demais, gordo demais ou por ser muito alto.

Segundo Coll, Marchesi e Palácios (2004), a autoestima é um conteúdo multidimensional e pode ter valorizações diferentes. As dimensões relevantes para a autoestima vão mudando através da idade. Ela está menos diferenciada nas idades precoces e vai se tornando complexa e diversificada de acordo com que o desenvolvimento avança.

A autoestima é um fator muito importante na adolescência, pois é nessa fase em que as mudanças corporais acontecem e o adolescente não está preparado para tal acontecimento. A mesma pode ter várias valorizações diferentes.

A estética é um fator importante na autoestima do adolescente. "A estética está em estreita relação com a cultura dos povos, é ditada pelas normas e padrões impostos pela sociedade." (KOVÁCS et al., 2008, p.128).

É através da estética que o indivíduo se sente mais adepto às exigências da sociedade.

O fenômeno também acontece com adolescentes inibidos, que têm medo de falar em público e não se enturmam. Beildel e Turner (1998 apud BERGER, 2013, p.54) traz que "o medo de falar em público [...] é um traço que os psicólogos chamam de inibição que pode se tornar uma característica denominada fobia social".

Muitos desses adolescentes que sofrem de inibição tem essa característica chamada de fobia social e sofrem com a mesma.

\section{O Conhecimento de si mesmo em crianças de seis anos até o início da adolescência}

Durante essa faixa, o conhecimento do eu dessas crianças ainda está na fase de construção e a valorização também se encontra aflorada. 
Id on Line Revista Multidisciplinar e de Psicoloqia

Id on Line Multidisciplinary Journal and Psycology

Segundo Souza (2011), para o filósofo Sócrates o conhecimento de si mesmo implicava muito no próprio conhecimento de nossas ações, de nossa vida e dos nossos desejos. Para o mesmo, a sabedoria seria constituída em vencer a si mesmo.

Para Coll, Marchesi e Palácios (2004) o autoconceito envolve um processo de construção do conhecimento de si mesmo e aumenta durante a infância e da adolescência. Na faixa dos 6 aos 12 anos, as crianças se descrevem em um processo continuado de mudanças e de uma complexidade crescente. As mudanças ocorrem nos aspectos estruturais do autoconceito quanto aos conteúdos de utilizar a si mesmo como algo referente dos 6 aos 8 anos e as comparações com os outros para se definir.

Como citado acima, nessa fase de mudança da infância para a adolescência ocorre o autoconceito, que é um processo de construção do conhecimento de si mesmo. Os aspectos estruturais do autoconceito e os conteúdos vão mudando e o adolescente em vez de utilizar a si mesmo como referente, passa a usar relações interpessoais e comparações com os outros.

No início da adolescência começa a aparecer a crise de identidade e, junto com ela, vem problemas com a autoestima. $\mathrm{O}$ bullying surge exatamente nessa fase quando o adolescente se encontra mais sensível e mais vulnerável a certos tipos de brincadeiras que acabam gerando agressões físicas e mentais.“[...] Parece claro que o comportamento superior do adulto depende, fundamentalmente, da experiência na infância”. (CAMPOS, 2011, p.26)

Esta ideia do autor traz que o comportamento do ser humano na fase adulta reflete suas experiências vividas na infância.

Segundo Bezerra (et al., 2012), as crianças que são alvos das agressões geralmente apresentam comportamento ou características que fogem do padrão do grupo, seja porque é o mais estudioso, ou o que tem menor rendimento, o de ser de cor/etnia diferente da maioria do grupo, etc.

Na infância, a criança passa por uma etapa útil, e para isso Krueger (2015) vem trazer que "a infância é uma etapa biologicamente útil [...] cuja conquista dura toda a infância e adolescência e define a estruturação própria destes períodos existenciais”. (p.02).

Para Berger (2013), os pré-escolares se sentem mais velhos e mais experientes do que as crianças menores. Colaborando com o pensamento deste autor, o mesmo vem trazer que: 
exagerada é, no caso de um pré-escolar, sinal de problemas psicossociais.) Os préescolares normalmente não têm esse problema; as crianças de 2 a 6 anos costumam ter uma impressão muito otimista de si mesmas. (p.177)

Segundo o autor da citação acima, os pré-escolares são mais seguros de si, acreditam que podem vencer corridas, fazer contas sem errar e saltar de maneira perfeitamente bem. Elas gostam de fazer várias tarefas e esperam que os demais sejam o público para suas apresentações e querem que essas pessoas as aplaudam no final.

\section{Suicídio}

Para Turecki (1999), o suicídio é um fenômeno complexo que é determinado pela interação de diversos fatores, tais como a constituição biológica do indivíduo, sua história pessoal, eventos circunstanciais e o meio ambiente.

Kóvacs (et al., 2008, p. 113) vem trazer que o suicídio é um ato que envolve questões individuais, que vão se acumulando no decorrer da vida, incluindo fatores ambientais, constitucionais, psicológicos e culturais. Para se chegar ao ato suicida, algumas particularidades devem ser consideradas. Alguns tipos dessas particularidades seriam o alcoolismo, doenças crônicas, doenças degenerativas ou dolorosas, estrutura familiar, tolerância às frustrações e o meio em que se vive: o social, religioso e cultural.

Segundo Borges (2004 apud SEMINOTTI; PARANHOS e THIERS, 2006), analisando sobre o comportamento suicida, ressaltam que o mesmo pode ser classificado em três categorias: ideação suicida, tentativa de suicídio e suicídio consumado.

Por isso é correto afirmar que "o indivíduo em crise se encontra em uma luta para manter o equilíbrio entre si e o meio [...] o que a leva a ver a morte como única saída”. (SEMINOTTI; PARANHOS e THIERS, 2006, p.01).

Para Kóvacs (et al., 2008, p. 113), o suicídio de forma mais ampla inclui processos autodestruitivos inconscientes e as tentativas de suicídio são manifestações de autodestruição em que a pessoa não sabe se viverá, pois a consciência do risco de morte pode ser muito vaga ao ponto de não saber dizer se é um ato inconsciente ou consciente.

De acordo com Benincasa e Rezende (2006), em adolescentes há atualmente a compreensão de que a depressão maior é comum, debilitante e recorrente, envolvendo um alto 
Id on Line Revista Multidisciplinar e de Psicoloqia

Id on Line Multidisciplinary Journal and Psycology

grau de morbidade e mortalidade, especialmente através do suicídio, constituindo-se em uma das principais preocupações da saúde pública e que, na maioria dos casos, não é identificada, nem encaminhada para tratamento.

Para Baggio, Palazzo e Arts (2009), o suicídio se constitui em um importante problema de saúde pública. O mesmo está mundialmente entre as dez principais causas de morte, entre as faixas etárias de 15 e 34 anos. As taxas variam de acordo com o contexto social, meios utilizados, gênero e faixa etária. Os comportamentos de risco entre adolescentes em relação com os fatores sociais e ambientais têm aumentado o número de mortes prematuras.

Segundo Araújo, Vieira e Coutinho (2010), apesar de não existir uma definição única e aceitável, sabe-se que existe um desejo consciente de morrer e a noção clara do que o ato feito pode resultar.

Araújo, Vieira e Coutinho (2010) traz que, com frequência, o comportamento suicida na literatura é classificado em três categorias: ideação suicida, tentativa de suicídio e suicídio consumado. Apesar de haver poucos dados disponíveis sobre os mesmos, em um dos extremos temos que a ideação suicida seria como: ideias, pensamentos, planejamento e desejo de se matar.

Segundo Werlang, Borges e Fensterseifer (2005 apud ARAÚJO; VIEIRA e COUTINHO, 2010) apesar de haver poucos dados disponíveis, a ideação suicida seria pensamentos, ideias, planejamento e desejos de se matar e, no outro, o suicídio consumado, com a tentativa de suicídio.

Para as tentativas de suicídio, Souza (et al., 2010) afirmam que "o suicídio é a terceira principal causa de morte na adolescência. Ideação suicida consiste em tentativas de suicídio, nesse sentido seria o primeiro passo para que a atitude se finalize.” (p. 02)

Baggio, Palazzo e Arts (2009) afirmam que o comportamento suicida costuma ser considerado como variando em um continuum, resultando ou não em morte. Corroborando com esta ideia, Berger (2013) vem trazer que:

Se a ideia de suicídio eventualmente leva ou não a um plano ou uma tentativa de suicídio, e à morte, depende de inúmeros fatores que variam de comunidade para comunidade. Na adolescência, cinco dos fatores mais influentes são: disponibilidade de meios letais, principalmente armas, supervisão dos pais, álcool e outras drogas, sexo, posicionamento em relação ao suicídio na cultura. (p.289) 
O suicídio para os jovens é bastante conhecido em sua cultura. Adolescentes que consomem álcool e outras drogas podem usufruir desse meio para se chegar ao suicídio. $\mathrm{O}$ mesmo leva inúmeros fatores para se ocorrer.

Para tentativas de suicido, Diekstra (et al., 1995 apud BERGER, 2013, p.289) traz que os especialistas preferem mais essa expressão de tentativa, em vez de o suicídio fracassado

\section{Relação entre Bullying e suicídio em adolescentes}

Segundo Bezerra (et al., 2012), o Bullying é responsabilizado atualmente por inúmeros casos de grave ameaça e violência no mundo inteiro ocorrido, em maior parte, no ambiente escolar.

Para Assis (et al., 2006) o termo em inglês para o bullying se refere a uma denominação diferenciada para a violência, evidenciando uma repercussão negativa da violência nas relações, encontrado principalmente no ambiente escolar.

Segundo Assis (et al., 2006) o bullying caracteriza-se por atos repetitivos de opressão, tirania, agressão e dominação de pessoas ou grupos sobre outras pessoas ou grupos. Muitas vezes atos de violência contínua.

Bullying e suicídio são dois fenômenos totalmente interligados, pois, quando um acontece, provavelmente o outro acontecerá. Vários casos no mundo todo já foram confirmados em que a maioria dos jovens se suicida por conta de não suportarem mais a pressão sofrida pelo bullying.

Existem muitos casos que mostram que o bullying acontece mundialmente. Alguns dos relatos abaixo mostram casos envolvendo este fenômeno. Segundo Albino e Terêncio (2012) em 2009, dois garotos de 11 anos, estudantes dos Estados de Massachusetts e Geórgia, nos EUA, suicidaram-se por motivos relacionados ao bullying em um intervalo aproximado de duas semanas.

Segundo o site DN Portugal (2011) outro caso muito forte aconteceu no filho de um homem chamado Allan L. Beane, no qual o mesmo confirmou que seu filho "havia se suicidado depois de sofrer um longo período de violência causada pelo bullying; o jovem havia se afundado no consumo de substâncias tóxicas levando-o à morte". Para o pai da vítima, o 
Id on Line Revista Multidisciplinar e de Psicoloqia

Id on Line Multidisciplinary Journal and Psycology

bullying também pode levar uma criança a aderir a uma gangue, uma seita, um grupo intolerante ou a um grupo de toxicodependentes.

Bezerra (et al., 2012) vem trazer outro caso muito chocante que aconteceu em janeiro do ano de 2013 no interior do estado de São Paulo:

Edimar Aparecido Freitas, de 18 anos, invadiu a escola onde havia estudado, no município de Taiúva, em São Paulo, com um revólver na mão. Ele feriu gravemente cinco alunos e, em seguida, matou-se. Obeso na infância e adolescência, ele era motivo de piada entre os colegas. (p. 04).

Este caso percorreu em sites de jornais. Segundo o site Último Segundo Brasil (2011), Edmar havia acabado de se formar no ensino médio, entrou na escola durante as férias, atirou em seis estudantes, em uma professora e no caseiro. Ninguém morreu, somente o atirador, pois o mesmo suicidou-se após o ocorrido, porém deixou feridos e sequelas nas vítimas.

Para Neto (2005), nos casos em que alunos armados invadiram as escolas e atiraram contra colegas e professores, esses jovens eram vítimas de bullying e recorreram às armas para combater o poder que os afetavam.

Segundo o site G1 (2014), o bullying motivou um garoto chamado Hawkins, de 14 anos, ao suicídio nos EUA. Segundo sua mãe, o garoto era vítima de abuso físico e emocional e teria usado a arma do pai para se matar, pois havia sofrido bullying por muitos anos pelos alunos da escola aonde estudava e não conseguiu suportar. $\mathrm{O}$ mesmo foi encontrado morto no banheiro da sua escola, a Greenwood Lakes.

O site Último Segundo (2012) relatou outro caso muito grave, submetido a uma jovem de 15 anos de idade que se jogou em uma linha de trem na cidade de Nova York, cujo nome da vítima seria Felícia Garcia. A mesma teria reclamado assédio de jogadores do time de futebol americano da escola a qual frequentava. Alguns de seus amigos declararam para o site que a Felícia era afetada, pois usava piercings e viveu em um orfanato e outros afirmaram que os jogadores de futebol americano haviam espalhado boatos sexuais sobre a mesma. 
Id on Line Revista Multidisciplinar e de Psicoloqia

Id on Line Multidisciplinary Journal and Psycology

\section{Metodologia}

Para o estudo deste artigo foi utilizado um levantamento bibliográfico através de livros e publicações científicas.

Para a ABNT (2003, p.03), a estrutura de um artigo científico é constituída por elementos pré-textuais: antes da escrita; textuais: no decorrer da escrita e pós-textuais: após o término da escrita.

Segundo Roman, Marchi e Erdmann (2013), a escolha entre diferentes métodos de pesquisa depende muito do objetivo que está pesquisando, que se está tentando explicar.

Para Galvão (2009), realizar um levantamento bibliográfico é se potencializar intelectualmente com o conhecimento coletivo para se ir além.

Nesse sentido, Galvão (2009) traz que o levantamento bibliográfico pede por um planejamento, sendo primordial fazê-lo em linguagem verbal escrita, seja qual for a temática que será abordada na pesquisa científica. É também uma pesquisa qualitativa, por não se utilizar de métodos estatísticos.

"A pesquisa qualitativa implica uma ênfase nas qualidades das entidades e nos processos e significados que não são examinados ou medidos experimentalmente quanto à quantidade, volume, intensidade ou frequência." (DENZI e LINCOLN 2006 apud ROMAN; MARCHI e ERDMANN, 2013, p.133).

Para os estudos qualitativos em uma pesquisa científica, Godoy vem trazer que:

\footnotetext{
Os estudos denominados qualitativos têm como preocupação fundamental o estudo e a análise do mundo empírico em seu ambiente natural. Nessa abordagem valoriza-se o contato direto e prolongado do pesquisador com o ambiente e a situação que está sendo estudada. No trabalho intensivo de campo, os dados são coleta dos utilizandose equipamentos como videoteipes e gravadores ou, simplesmente, fazendo-se anotações num bloco de papel (GODOY, 1995, p. 62).
}

Foram pesquisados autores, tais como: Cézar Coll, Álvaro Marchesi, Jesús Palácios, Evaldo A. D' Assumpcão e Vivina do C. Rios. O tempo para a realização desse artigo foi em torno de seis meses com supervisão da orientadora. 
Id on Line Revista Multidisciplinar e de Psicoloqia

Id on Line Multidisciplinary Journal and Psycology

\section{Considerações Finais}

Conclui-se através dos estudos que o bullying é um fenômeno praticado em todo o mundo e seu termo vem do inglês. A prática vista para a violência envolvendo o mesmo chamase "fenômeno bullying" pelos autores que se dedicam a esse assunto.

O bullying se classifica em três categorias: os autores, as vítimas e as testemunhas e existem dois tipos para a prática do mesmo: a direta e a indireta. Fatos envolvendo o bullying são vistos não só no Brasil, mas no mundo todo, evidenciando uma realidade perversa entre os jovens.

Este fenômeno acontece em cenários ao redor do mundo, mas os mais presentes são no ambiente escolar, nas redes sociais de internet e na própria internet (chamado de cyberbullying), no qual o agressor por meio de aparelhos eletrônicos, seja anonimamente ou não, humilha, denigre e difama a vítima.

As consequências envolvendo esse fenômeno são traumáticas e geram danos terríveis para a vida da vítima e um deles está ligado à autoestima.

Os adolescentes com baixa autoestima, tem a vulnerabilidade de dificultar a interação grupal e isso aumenta a probabilidade de serem vítimas do bullying por não se entrosarem com os demais em um grupo. O bullying implica muito na autoestima tanto de meninas, como de meninos, em diferentes formas.

Implicações do bullying na autoestima e pressões na vida pessoal da vítima podem gerar o suicídio, pois o mesmo é um fenômeno complexo que é determinado por diversos fatores. $\mathrm{O}$ adolescente em crise se encontra no meio de uma luta entre si e o meio social em que vive e, se esse equilíbrio entre ambos for alterado, a morte seria sua única saída.

O suicídio entre jovens no mundo todo está aumentando cada vez mais. O mesmo é a terceira causa de morte na adolescência. Este fenômeno é classificado em três categorias: ideação suicida, tentativa de suicídio e suicídio consumado.

Casos no mundo inteiro de jovens que se suicidaram por conta do fenômeno bullying são inúmeros e ocorrem, em sua maior parte, no ambiente escolar.

A pesquisa não pretende esgotar as discussões sobre o tema, mas contribuir para trazer mais evidências sobre o assunto e suas articulações. 
Id on Line Revista Multidisciplinar e de Psicoloqia

Id on Line Multidisciplinary Journal and Psycology

\section{Referências}

ABNT, Associação Brasileira de Normas Técnicas. 2003

ALBINO, Priscilla Linhares; TERÊNCIO, Marlos Gonçalves. Considerações críticas sobre o fenômeno do Bullying: do conceito ao combate e à prevenção. Disponível em: http://portal.pmf.sc.gov.br/arquivos/arquivos/pdf/18 $03 \quad 2010 \quad 15.21 .10 .2 \mathrm{af5ca} 0 \mathrm{c} 78153 \mathrm{~b} 8 \mathrm{~b} 4 \mathrm{a} 479$ 93d66a51436.pdf. Acesso em: 14 set. 2012.

ALMEIDA, Kathanne Lopes; SILVA, Anamaria Cavalcante; CAMPOS, Jocileide Sales. Importância da identificação precoce da ocorrência do bullying: uma revisão de literatura. Rev Pediatr, 9(1): 8-16, jan./jun. 2008. Disponível em: http://www.cores.org.br/biblioteca/bullying.pdf. Acesso em: 01 mai. 2015.

ALVES, Maria Bernardete Martins; ARRUDA, Susana Margaret de. Como elaborar um artigo científico. Modelo de Artigo de periódico baseado na NBR 6022, 2003. Disponível em: http://www.bu.ufsc.br/ArtigoCientifico.pdf. Acesso em: 16 abr. 2015.

ARAÚJO, Luciene da Costa; VIEIRA, Kay Francis Leal; COUTINHO, Maria da Penha de Lima. Ideação suicida na adolescência: um enfoque psicossociológico no contexto do ensino médio. Universidade Federal da Paraíba, João Pessoa, Brasil, 2010. Disponível em: http://www.scielo.br/scielo.php?script=sci arttext\&pid=S1413-82712010000100006. Acesso em: 14 fev. 2015.

ASSIS, Simone G.; AVANCI, Joviana Q.; OLIVEIRA, Raquel V.C. Violência escolar e autoestima de adolescentes. Cadernos de Pesquisa, v. 36, n. 127, p. 35-50, jan./abr. 2006. Disponível em: http://www.scielo.br/pdf/cp/v36n127/a0336127.pdf. Acesso em: 21 abr. 2015.

ASSUMPÇÃO, Evaldo A. D'. Sobre o viver e o morrer: manual de Tanatologia e Biotanatologia para os que partem e os que ficam. 2 ed. ampliada - Petrópolis: Vozes, 2011.

BAGGIO, Lissandra; PALAZZO, Lílian S.; AERTS, Denise Rangel Ganzo de Castro. Planejamento suicida entre adolescentes escolares: prevalência e fatores associados. Programa de Pós-graduação em Saúde Coletiva, Universidade Luterana do Brasil, Canoas, Brasil. Cad. Saúde Pública vol.25 no.1 Rio de Janeiro Jan. $2009 . \quad$ Disponível em: http://www.scielo.br/pdf/csp/v25n1/15.pdf. Acesso em: 14 fev. 2015.

BALbINO, Vivina do C. Rios. Psicologia e Psicologia escolar no Brasil. São Paulo: Summus, 2008

BANDEIRA, Cláudia de Moraes; HUTZ, Claudio Simon. As implicações do bullying na autoestima de adolescentes. 2010. Disponível em:

http://www.scielo.br/pdf/pee/v14n1/v14n1a14.pdf. Acesso em: 14 set. 2012

BERGER, Kathleen Stassen. O desenvolvimento da pessoa: da infância à terceira idade. Rio de Janeiro: LTC, 2013. 
Id on Line Revista Multidisciplinar e de Psicoloqia

Id on Line Multidisciplinary Journal and Psycology

BEZERRA, Fabiana Correia; BARRETO, Polliana de Luna Nunes; SOUSA, Terezinha Matias da Silva; MENDES, Francilda Alcantara. Bullying: uma revisão da Literatura. II Colóquio Sociedade, Políticas Públicas, Cultura e Desenvolvimento-CEURCA, ISSN 2316- 3089.Universidade Regional do Cariri-URCA, Crato-Ceará-Brasil. 2012. Disponível em: http://www.urca.br/coloquioeconomia/IIcoloquio/anais/trab_educ_com_desenv/1.pdf. Acesso em: 26 mar. 2015.

CALBO, Adriano Severo; BUSNELLO, Fernanda de Bastani; RIGOLI, Marcelo Montagner; SCHAEFER, Luiziana Souto; KRISTENSEN, Christian Haag. Bullying na escola: comportamento agressivo, vitimização e conduta pró-social entre pares. 2009. Disponível em: http://www.contextosclinicos.unisinos.br/pdf/62.pdf. Acesso em: 11 out. 2012

CAMPOS, Herculano Ricardo; JORGE, Samia Dayana Cardoso. Violência na escola: uma reflexão sobre o bullying e a prática educativa. Em Aberto, Brasília, v. 23, n. 83, p. 107-128, mar. 2010. http://www.emaberto.inep.gov.br/index.php/emaberto/article/viewFile/1636/1302. Acesso em: 25 fev. 2015.

COLL, Cézar; MARCHESI, Álvaro; PALÁCIOS, Jesús. Desenvolvimento psicológico e educação.Trad. Fátima Murad - 2. Ed. - Porto Alegre: Artmed, 2004.

CAMPOS, Dinah Martins de Souza. Psicologia da aprendizagem. 39. ed. Petrópolis: Vozes, 2011.

COLOVINI, Cristian Ericksson; COSTA, Mara Regina Nieckel. O fenômeno Bullying na percepção dos professores. $2007 . \quad$ Disponível em: http://guaiba.ulbra.br/seminario/eventos/2007/artigos/psicologia/221.pdf. Acesso em: 15 set. 2012.

D'URSO, Clarice. Cyberbullying: Um desafio para o direito. Disponível em: http://www.oabsp.org.br. Acesso em: 02 mai. 2015

FEIJÓ, Ricardo Becker; RAUPP, Ana Paula Gonçalves; JOHN, Angela Beatriz. Eventos estressores de vida e sua relação com tentativas de suicídio em adolescentes. 1999. Disponível em: $\quad$ http://bases.bireme.br/cgibin/wxislind.exe/iah/online/?IsisScript=iah/iah.xis\&src=google \&base=ADOLEC\&lang=p\&nextA ction=lnk\&exprSearch=238803\&indexSearch=ID. Acesso em: 17 nov. 2012.

FREIRE, Alane Novaes; AIRES, Januária Silva. A contribuição da psicologia escolar na prevenção e no enfrentamento do Bullying. Maringá, 2012. Disponível em: http://www.scielo.br/scielo.php?script=sci arttext\&pid=S1413-85572012000100006. Acesso em: 17 nov. 2012.

GALVÃO, Maria Cristiane Barbosa. O levantamento bibliográfico e a pesquisa científica. 2009, disponível

em: http://www2.eerp.usp.br/Nepien/DisponibilizarArquivos/Levantamento_bibliografico_CristianeG alv.pdf. Acesso em: 14 mar. 2015 
Id on Line Revista Multidisciplinar e de Psicoloqia

Id on Line Multidisciplinary Journal and Psycology

GODOY, Arllda Schmidt. Introdução à pesquisa qualitativa e suas possibilidades: Uma revisão histórica dos principais autores e obras que refletem esta metodologia de pesquisa em Ciências Sociais. Revista de Administração de Empresas, São Paulo, v. 35, n. 2, p. 57-63, Mar./Abr. 1995.

HAWLEY, P. H. (1999). The ontogenesis of social dominance: A strategy-based evolutionary perspective. Developmental Review, 19, 97-132.

IDALGO, Manoel de Oliveira. Bullying escolar e educação. Disponível em: http://www.uel.br/grupoestudo/gaes/pages/arquivos/MANOEL\%20HIDALGO\%20artigo\%20\%20GT\%2002\%20\%20SECAO\%2002.pdf. Acesso em: 17 set. 2012

KRUEGER, Magrit Froehlich. A relevância da afetividade na educação infantil. Associação Educacional Leonardo da Vinci - ASSELVI. Disponível em: http://www.posuniasselvi.com.br/artigos/rev03-04.pdf. Acesso em: 02 mai. 2015

LEÃO, Letícia Gabriela Ramos. O fenômeno Bullying no ambiente escolar. Revista FACEVV, Vila Velha, n. 4, p. 119-135, Jan./Jun. 2010.

LIMA, Cláudia Turatti. Bullying e seus efeitos no ambiente escolar. 2010. Disponível em: http://www.slideshare.net/guest44dfeb3/artigo-bullying-e-seus-efeitos-na-parendizagem Acesso em: 16 set. 2012.

LISBOA, Carolina; BRAGA, Luiza de Lima; EBERT Guilherme. O fenômeno bullying ou vitimização entre pares na atualidade: definições, formas de manifestação e possibilidades de intervenção. Contextos Clínicos, vol. 2, n. 1, janeiro-junho 2009. São Leopoldo. Disponível em: http://pepsic.bvsalud.org/scielo.php?pid=S1983-34822009000100007\&script=sci_arttext. Acesso em: 14 set. 2012.

LISBOA, C. S. M. Comportamento agressivo, vitimização e relações de amizade em crianças em idade escolar: fatores de risco e proteção. 2005. Tese (Doutorado em Psicologia do Desenvolvimento). Programa de Pós-Graduação em Psicologia do Desenvolvimento. Instituto de Psicologia. Universidade Federal do Rio Grande do Sul, Porto Alegre, 2005.

NETO, Aramis A. Lopes. Bullying: comportamento agressivo entre estudantes. Jornal de Pediatria - Vol. 81, No5(Supl). 2005. Disponível em: http://www.scielo.br/pdf/jped/v81n5s0/v81n5Sa06.pdf. Acesso em: 26 mar. 2015.

REBELO JR, Salvador Loureiro. Bullying: Uma realidade cruel no contexto escolar. 2007. Disponível em: http://www.psicopedagogia.com.br/artigos/artigo.asp?entrID=946. Acesso em: 14 set. 2012

ROMAN, Darlan José; MARCHI, Jamur Johnas; ERDMANN, Rolf Hermann. A abordagem qualitativa na pesquisa em administração da produção no Brasil. REGE, São Paulo, v. 20, n. 1, p. 131-144, jan./mar. 2013.

SEMINOTTI, Elisa Pinto; PARANHOS Mariana Esteves; THIERS Valéria de Oliveira. Intervenção em crise e suicídio: Análise de artigos indexados. 2006. Disponível em: http://www.psicologia.pt/artigos/textos/A0297.pdf Acesso em: 16 nov. 2012 
Id on Line Revista Multidisciplinar e de Psicoloqia

Id on Line Multidisciplinary Journal and Psycology

SITE DN Portugal. Bullying pode levar ao suicídio, diz pai de uma vítima. 2011. Disponível em: http://www.dn.pt/inicio/portugal/interior.aspx?content_id=1853433. Acesso em: 18 nov. 2012

SITE G1. Globo.com. Bullying motivou suicídio de menino em escola dos EUA, diz mãe. 2014. Disponível em: http://g1.globo.com/mundo/noticia/2014/09/bullying-motivou-suicidio-de-menino-em-escola-dos-eua-dizmae.html. Acesso em: 18 abr. 2015

SITE Último Segundo. Sobreviventes de caso semelhante ao do Rio revivem trauma. 2011. Disponível em: http://ultimosegundo.ig.com.br/brasil/sp/sobreviventes+de+caso+semelhante+ao+do+rio+revivem +trauma/n1300036730840.html. Acesso em: 26 mar. 2015

SITE Último Segundo. Amigos culpam bullying por suicídio de menina de 15 anos nos EUA. 2012. Disponível em: http://ultimosegundo.ig.com.br/mundo/nyt/2012-10-30/amigos-culpambullying-por-suicidio-de-menina-de-15-anos-nos-eua.html. Acesso em: 02 mai. 2015

SOUZA, Luciano Dias de Mattos; ORES, Liliane; OLIVEIRA, Gabriela Teixeira de; CRUZEIRO, Ana Laura Sica; SILVA, Ricardo Azevedo; PINHEIRO, Ricardo Tavares; HORTA, Bernardo Lessa. Ideação suicida na adolescência: prevalência e fatores associados. J Bras Psiquiatr. 2010. Disponível em: http://www.scielo.br/pdf/jbpsiq/v59n4/04.pdf. Acesso em: 14 fev. 2015.

SOUZA, Michel Aires de. Sócrates: a filosofia como conhecimento de si mesmo. 2011. Disponível em: https://filosofonet.wordpress.com/2011/07/14/socrates-a-filosofia-como-conhecimento-de-simesmo. Acesso em: 08 mai. 2015.

TREVISOL, Maria Teresa; DRESCH, Daniela. Escola e bullying: a compreensão dos educadores. Revista Múltiplas Leituras, v. 4, n. 2, 2011. Disponível em: https://www.metodista.br/revistas/revistas-ims/index.php/ML/article/viewFile/2842/2905 Acesso em: 08 mai. 2015.

TURECKI, Gustavo. 2008. O suicídio e sua relação com o comportamento impulsivo-agressivo. Disponível em:

http://www.scielo.br/scielo.php?script=sci arttext\&pid=S1516-44461999000600006. Acesso em: 16 nov. 2012.

Como citar este artigo (Formato ABNT):

BARBOSA, A. Bulling e sua Relação com o suicK.L.; PARENTE, T.D.L.; BESERRA, M.M.M.; MARANHÃO, T.L.G. Bulling e sua relação com o suicídio na adolescência. Id on Line Revista Multidisciplinar e de Psicologia, Set-Out de 2016, vol.10, n.31, p. 202-220. ISSN 1981-1179.

Recebido: 04/08/2016.

Aceito: $15 / 08 / 2016$ 